\title{
Moving from the NHS: the benefits of joining Denplan
}

Now more than ever with so many unknowns during the pandemic, a sense of security for your business is vital. At Denplan, part of Simplyhealth, we have spent more than 35 years supporting dentists to transition into Denplan private payment plans, giving financial security and support when it's most needed.

We understand that it can be difficult running a fully NHS practice, so let us help you to consider your options and explore why integrating Denplan could help you take control of your business. Our team of experienced Business Development Consultants are on hand to conduct a financial analysis, putting you in control by creating a personalised stepby-step plan to roll out the right payment plans for you and your patients.

\section{Pandemic has made us take stock}

The pandemic has made many dentists stop and think about what they want and what is important to them. Our member dentists have had the comfort of regular payments from Denplan patients, and most of all they have had comprehensive business support and guidance from Denplan enabling them to keep their business thriving.

'Denplan helped us get through this pandemic in different ways. With all that was happening, it gave us much needed security - both with patients paying Denplan fees, and through comprehensive business support for our practice. Denplan has helped make our practice more secure for whatever happens in the future, which is a great relief for us all.' Sarah Bond, Practice Manager at Anterior Dental Care in Kettering.

\section{How has Denplan helped practices during the pandemic?}

Denplan has supported its members throughout the pandemic with vital business support including:

- Marketing materials, including instant resources with everything from personalised posters to answerphone messages

- Virtual training delivery, enabling key CPD to be completed, as well as leading industry seminars linking up the profession and bespoke online practice training

- Financial support, including assistance loans, reduced admin charges, and additional fee rate review opportunities

- Huge $£ 2$ million investment in PPE from Simplyhealth enabling all Denplan practices access to the safety measures needed to be up and running

- Access for the whole practice team to our GP and Employee Assistance Programme, providing vital mental health support in times of crisis

- Clinical support helping dentists navigate all the national governance and clinical guidance by creating clear and meaningful support documents, enabling more than $75 \%$ of our member practices to re-open the day they were given the national go-ahead.

\section{Now is the time}

For more than three decades, NHS transitions have been a huge part of who Denplan is. We work with you to understand your vision and understand your goals for your future. Denplan's membership support is comprehensive both before, during, and after the NHS transition.

A critical business eye is vital for the survival of practices. Denplan's Business Development Team based all over the UK are talking to practices about fee-setting and conducting financial reviews to support practices every day. They are growing their Denplan patient numbers in times of crisis - and you can too!

'Obviously the pandemic this year has brought serious challenges for everyone but Denplan has been amazing with its support, including supplying all members with much-needed PPE, and the continued monthly income freed us from the anxiety felt by many other dentists. We were able to recover quickly after lockdown and are confident about the future. We're still registering around 60 new patients every month, which is fantastic.'

\section{Adam Hunter, Principal Dentist at Parkview Dental Centre}

\section{What are my options?}

Depending on your circumstances, you can adopt an approach that is best suited to your practice. Whether you're ready to move from the NHS to private dentistry in full, or looking to do it one dentist at a time. Each option can be tailored to best suit the approach you want to take.

Our consultants have built strong relationships with their dentists over the years. In many ways they become an extension of a dentist's team and our new members quickly discover what a fantastic resource and support these consultants are to help them introduce Denplan payment plans and run a successful private or mixed practice.

\section{Dedicated member benefits to support your practice}

As a member dentist, you will receive a wealth of inclusive support services, helping you to focus on giving your patients the very best dental care, including:

- A dedicated Business Development Consultant to help and support you with business and financial planning to help make your practice more profitable

- A Practice Support Advisor for your everyday questions

- Professional and regulatory advice and guidance on a range of issues such as compliance and regulations, clinical concerns and contractual queries

- Online dashboard offering a host of useful information

- Practice marketing support to help you promote your business including personalised marketing plans and patient profiling

- Access to free and subsidised practice training and events

- Practice and patient recruitment campaigns to reward growth

- Flexibility to keep your NHS commitment but also take on Denplan payment plan patients with our Principal-only or Associate transition option.

Take your first step today by visiting: www.denplan.co.uk/go-private-BDJ or call us on 08001699962. 